See Article page e11.

\section{Commentary: Calpain inhibition: A novel strategy to treat chronic myocardial ischemia}

\author{
Harold L. Lazar, MD
}

Calpains are a group of calcium-activated cysteine proteases that, when activated during myocardial ischemia, contribute to increased myocardial fibrosis. ${ }^{1}$ This is thought to occur by activation of transforming growth factor beta, which promotes collagen formation. ${ }^{2}$ In this issue of the Journal, Potz and colleagues ${ }^{3}$ studied the effects of calpain inhibition (CI) in a hypercholesterolemic swine model with chronic myocardial ischemia secondary to ameroid constriction of the left circumflex artery. Following 5 weeks of high-dose CI, the expression of collagen in ischemic and nonischemic myocardial tissue was significantly decreased. CI had no significant effect on hemodynamic parameters and did not alter the derangement in glucose metabolism or the abnormal cholesterol and lipid levels. Based on their previous studies in the same swine model using CI, which showed increased blood flow and decreased myocardial apoptosis, ${ }^{4,5}$ the authors propose that CI may be used to treat chronic myocardial ischemia in patients who are not candidates for either coronary artery bypass graft surgery or percutaneous coronary intervention.

Although the authors are to be congratulated on performing a series of complex experiments on CI in a swine model with chronic ischemia, there are some limitations with this study. No histologic studies were performed to determine whether there was any evidence of myocardial necrosis. Therefore, it is unknown as to whether changes in collagen expression could be related to the amount of infarcted myocardial tissue and whether the extent of the infarction was equal among the

\footnotetext{
From the Division of Cardiac Surgery, Boston University School of Medicine, Boston, Mass.

Disclosures: Author has nothing to disclose with regard to commercial support.

Received for publication Dec 1, 2019; revisions received Dec 1, 2019; accepted for publication Dec 2, 2019; available ahead of print Dec 17, 2019.

Address for reprints: Harold L. Lazar, MD, Division of Cardiac Surgery, Boston University School of Medicine, 80 East Concord St, Boston, MA 02118 (E-mail: harold.1.lazar@gmail.com).

J Thorac Cardiovasc Surg 2022;163:e29-30

$0022-5223 / \$ 36.00$

Copyright (c) 2019 by The American Association for Thoracic Surgery

https://doi.org/10.1016/j.jtcvs.2019.12.007
}

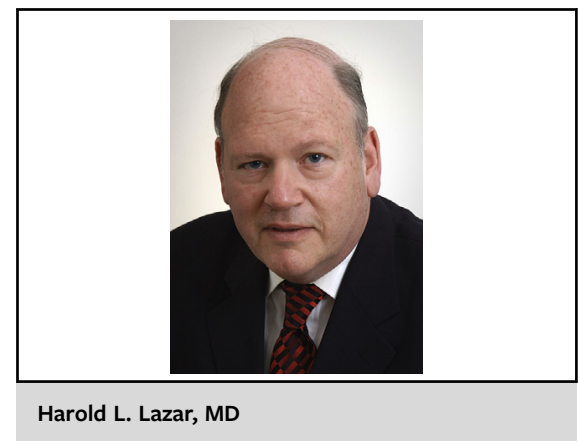

CENTRAL MESSAGE

In a swine model with chronic ischemia, calpain inhibition (Cl) decreased collagen formation and preserved myocardial cytoskeletal structure. CI may be used to treat chronically ischemic myocardium.

animal groups. Furthermore, the authors have not actually demonstrated that there was evidence of pathologic myocardial fibrosis in these specimens. Although these results suggest that $\mathrm{CI}$ may lead to improved cardiomyocyte integrity during chronic ischemia, they have not demonstrated improved function of this tissue. Changes in hemodynamics were assessed using Millar catheters, which is representative of global left ventricular function. The lack of data on regional wall motion is a limitation of this study. If $\mathrm{CI}$ is to be used clinically to treat patients with chronic ischemia who are not candidates for revascularization, it would be important to show that CI improves regional wall motion, thereby improving angina symptoms during exertion.

Patients with insulin-dependent diabetes and hypercholesterolemia who have diffusely diseased vessels not amenable to either coronary artery bypass graft surgery or percutaneous coronary intervention may benefit most from CI. In addition, CI may also have a role in the revascularization of acutely ischemic or infarcting myocardium following acute revascularization because of its potential to stabilize the cytoskeletal structure of the myocardium during reperfusion and ultimately limit fibrosis. The authors are to be encouraged to continue their work on CI and their efforts to bring this novel therapy into clinical practice. 


\section{References}

1. Letavernier E, Zafrani L, Perez J, Letavernier B, Haymann JP, Baud L. The role of calpains in myocardial remodeling and heart failure. Cardiovasc Res. 2012;96: $38-45$.

2. Li FZ, Cai PC, Song LJ, Zhou LL, Zhang Q, Rao SS, et al. Crosstalk between calpain activation and TGF-B1 augments collagen-I synthesis in pulmonary fibrosis. Biochem Biophys Acta. 2015;1852: 1796-804.
3. Potz BA, Sabe AA, Sabe SA, Lawandy IJ, Abid MR, Clements RT, et al. Calpain inhibition decreases myocardial fibrosis in chronically ischemic hypercholesterolemic swine. J Thorac Cardiovasc Surg. 2022;163:e11-27.

4. Potz BA, Sabe AA, Elmadhun NY. Calpain inhibition decreases myocardial apoptosis in a swine model of chronic myocardial ischemia. Surgery. 2015;158:445-52.

5. Sabe AA, Potz BA, Elmadhun NY. Calpain inhibition improves collateral dependent perfusion in a hypercholesterolemic swine model of chronic myocardial ischemia. J Thorac Cardiovasc Surg. 2016;151:245-52.
See Article page e11.

\section{Commentary: Calpains: Another piece of the cardiac fibrosis puzzle}

\author{
Mark R. Helmers, MD, and Pavan Atluri, MD
}

Myocardial fibrosis is a complex pathologic process that lies at the endpoint of a variety of cardiac diseases, ranging from coronary artery disease to hypertension to cardiomyopathies. ${ }^{1}$ Cardiac fibrosis can be regional or diffuse in pattern and results in both diastolic and systolic dysfunction, as well as malignant arrhythmias. ${ }^{2}$ Expanding our understanding of the molecular mechanisms that drive and perpetuate myocardial fibrosis is integral to the improvement of cardiac therapies.

In this issue of the Journal, Potz and colleagues ${ }^{3}$ report their findings on the effects of calpain inhibition (CI) on myocardial fibrosis in a porcine model of hypercholesterolemia and chronic myocardial ischemia. Calpains are a family of calcium-dependent, cysteine proteases that play a key role in myocardial fibrosis by activating transforming growth factor $\beta$ and resultant collagen synthesis. ${ }^{4}$ The authors induced chronic myocardial ischemia in high cholesterol diet-fed Yorkshire pigs via placement of an ameroid constrictor on the left circumflex artery. Pigs were treated with either no drug, low-dose CI, or high-dose CI. Myocardial tissue from ischemic and nonischemic territories was analyzed. CI was found to decrease fibrosis as well as

From the Division of Cardiovascular Surgery, Department of Surgery, University of Pennsylvania, Philadelphia, $\mathrm{Pa}$.

Disclosures: Authors have nothing to disclose with regard to commercial support.

Received for publication Jan 10, 2020; accepted for publication Jan 13, 2020; available ahead of print Feb 21, 2020.

Address for reprints: Pavan Atluri, MD, Division of Cardiovascular Surgery, Hospital of the University of Pennsylvania, 3400 Spruce St, 6 Silverstein Pavilion, Philadelphia, PA 19104 (E-mail: Pavan.Atluri@uphs.upenn.edu).

J Thorac Cardiovasc Surg 2022;163:e30-1

$0022-5223 / \$ 36.00$

Copyright (c) 2020 by The American Association for Thoracic Surgery

https://doi.org/10.1016/j.jtcvs.2020.01.012
Check for updates

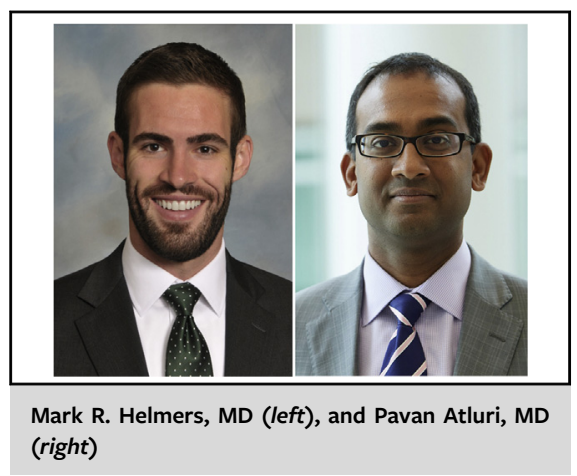

CENTRAL MESSAGE

For patients with ischemic heart

disease and metabolic syndrome, calpain inhibition may be a valu-

able addition to the growing armamentarium of antifibrotic cardiovascular therapies.

Jak/STAT/MCP-1 signaling in the swine. CI was also shown to influence expression of focal adhesion proteins as well as cytoskeletal and structural proteins. Interestingly, the authors found variable modulation of transforming growth factor $\beta$ and Jak/STAT/MCP-1 signaling in human ventricular fibroblast and rat fibroblasts, suggesting cell-type dependent effects of calpain signaling.

Although CI did not affect left ventricular hemodynamics or aortic pressures in the swine, the study did not involve any in vivo imaging. Although cardiovascular magnetic resonance imaging is expensive and limited in availability, late gadolinium enhancement and myocardial longitudinal relaxation time mapping enable accurate assessment and characterization of cardiac fibrosis. ${ }^{5}$ It is possible that cardiovascular magnetic resonance would have elucidated calpain-mediated ventricular remodeling in the swine. 